Review

\title{
Genomic-Led Potato Breeding for Increasing Genetic Gains: Achievements and Outlook
}

\section{Rodomiro Ortiz}

Department of Plant Breeding (VF), Swedish University of Agricultural Sciences (SLU), Sundsvagen 10 Box 101, SE2053 Lomma, Sweden;

Email: rodomiro.ortiz@slu.se

\section{ABSTRACT}

Potato is the third most important crop, after rice and wheat, in human diets worldwide. Genetic gains due to its crossbreeding for productivity per se appear to be stagnant in this tetraploid crop. Its genetic enhancement needs to overcome inherent barriers such as ploidy, outcrossing and heterozygosity. Pathogens and pests affect potato because they may infect the entire plant, including stems, leaves and tubers, thus leading to significant tuber yield loss. Hence, host plant resistance breeding remains key for improving the productivity of this crop. This article reviews recent research advances relevant to potato breeding emphasizing genomic resources, methods and tools for genetic analysis, mapping of genes and quantitative trait loci, and genomic prediction of breeding values (or genomic selection) for population improvement. In this regard, association genetics has provided insights onto genetic architecture and inheritance of priority breeding traits, as well as tagging them to DNA markers for their further use as aids for indirect selection. Early research results show the feasibility of genomic selection as a new breeding approach for a tetrasomic polyploid such as potato. This manuscript also highlights the proposed inbred line strategy for producing diploid $F_{1}$ true potato seed hybrids, and how its use may speed up and increase genetic gains in potato breeding; as well as promoting alleles through gene editing. The paper ends proposing a new interploidy breeding approach considering ploidy manipulations and incorporating genomic selection and gene editing for both population improvement and cultivar development.

KEYWORDS: Solanum tuberosum; cultivar development; $F_{1}$ true seed hybrid; gene editing; genomic selection; heterosis; polyploidy; tetrasomic inheritance

\section{INTRODUCTION}

The tetraploid ( $2 n=4 x=48$ chromosomes) potato (Solanum tuberosum L.) is the third most important food crop but its global trading only includes a small share (7\% in 2017) in fresh, frozen or seed markets [1]. This crop was domesticated about 10,000 years ago in Perú [2], although 
there are some evidences on the use of potato peels for food in southern Utah and south-central Chile nearly 13,000 years ago [3]. Research on sequencing the genome of the potato (landraces and cultivars) and its wild relatives reveals a great genetic variation and signatures of selection of genes controlling domestication traits [4]. It was also noticed key wild introgressions after polyploidy, thus taking wild alleles outside their geographic origin. Likewise, it seems that a few genes drove the early improvement of potato as well as that distinct loci were involved in the adaptation of both upland (S. tuberosum group Andigena) and lowland ( $S$. tuberosum groups Chilotanum and Tuberosum) groups.

Two potato introductions were brought, after Columbus voyages, from South America to Europe in the 16th Century and a few cultivars were grown therein in the 18th century [5]. Selection among seedlings (derived from true seed found in naturally set berries) from established virusinfected potatoes led to increasing the number of cultivars grown in the late 18th and early 19th centuries [5]. Late blight (caused by the oomycete Phytophthora infestans) eliminated most of these cultivars in the mid-19th century, thus reducing Europe's potato breeding gene pool. Thereafter new introductions (mostly from Chile) and their crossbreeding with the few surviving European cultivars led to increasing variation through the release of newly bred cultivars in the early 20th century in the northern hemisphere. During the 20th century several collecting trips for potato germplasm (native cultivars and wild species) were undertaken throughout Latin America with the aim of evaluating and using in crossbreeding such genetic resources for broadening the genetic base of the cultigen pool. It seems, however, that the many of the genes bear by most of modern bred cultivars trace to cultivars already grown in the early 20th century, thus suggesting a limited inbred gene pool.

Pedigree information allows assessing relatedness among cultivars and breeding clones, thus facilitating the crossing design among them and increasing the power of association genetics analysis. Coefficients of coancestry are derived from pedigree analysis to quantify relatedness among genotypes. Knowledge on pedigrees is also used for naming genes (particularly for host plant resistance) and tracing their identity. Hence, an online pedigree database with a web-accessible interface became available more than one decade ago with the aim of including all cultivars released worldwide and their parents [6]. Moreover, worldwide pedigree analysis over time reveals that the use of elite parental germplasm in crossbreeding led to developing outstanding potato cultivars [7]. Further analysis with single nucleotide polymorphisms (SNPs) found conserved genome segments bearing target genes from an elite parent in its derived offspring following five generations of selective breeding. SNPs are also useful for checking pedigree records in potato [8]. This pedigree-based research along with DNA fingerprinting also allows to identify genome segments that bear important genes related to target traits, thus 
facilitating potato breeding-by-design. Hence, it will be worth characterizing with SNPs any newly released cultivars.

Potato breeding nowadays faces several global challenges; i.e., delivering enough and quality food for the diets of a growing human population, fitting newly bred cultivars into sustainable farming, and offering a supply of bio-sources for the agri-food industry [9]. This article provides an overview on the advances in genomic-led breeding for potato, including its main achievements.

\section{GENETIC GAINS IN POTATO BREEDING}

Potato is a highly heterozygous, tetrasomic polyploid due to its four homolog chromosomes rather than two in diploid species, thus making its genetics complex [10]. The main breeding objective for this crop remains combining table or processing tuber quality with host plant resistance to many pathogens and pests affecting potato elsewhere, and suitable for being grown and stored. A recent breeding objective to address policy regarding sustainable intensification of potato farming is input-use efficiency to reduce the utilization of fertilizers and watering. Newly bred resilient cultivars are also necessary for growing potato under the changing climate, particularly in heat- and drought-prone sites. The fresh markets for table potato ask for cultivars whose tubers show a nice visual aspect (i.e., shape, depth of eyes, skin and flesh color) and cooking suitability, while the processing markets give priority to tuber chemical composition, particularly for low reducing sugars and appropriate specific gravity (or dry matter content). More recently, the potato industry is also asking for starch quality (amylose: amylopectin ratio), bioactive compounds such as antioxidants, micronutrients (vitamins, Fe, $\mathrm{Zn}$ ) and the relative ranking of carbohydrates as measured by the glycemic index; i.e., how fast food causes increases in blood glucose levels.

The main benefits brought by bred cultivars include increase incomes due to more tuber yield, decrease of pesticides owing to host plant resistance, and-last but not least-convenience food with enhanced quality for healthy diets. Crossbreeding is still the main approach for developing new potato cultivars and sometimes using its wild Solanum relatives that are available in gene banks worldwide. Population improvement with progeny testing may improve the rate of improvement in potato breeding. Selecting desired genotypes to become new potato cultivars is a challenging and time-consuming breeding task. Ploidy manipulations (scaling down and up chromosome numbers) and biotechnology (tissue culture, genetic engineering and genomics) offer means for accelerating the genetic enhancement of this crop.

Genetic gains for potato breeding in the USA since the late 19th century until the early 1990s were noted only for early maturity and overall tuber appearance but not for tuber yield per se, while chip-processing ability and dry matter content improved only for white-skin cultivars [11]. These findings relate to the end-users needs. For example, early maturity 
cultivars allow widening harvest periods and fitting into profitable "market windows". Likewise, tuber quality traits are priority for table and processing potatoes. The lack of improving tuber yield per se could ensue from its negative correlation with maturity [11], the challenge of combining it with tuber quality (often differing as per the needs of growers, processors and consumers) and host plant resistance to various pathogens and pests [12], and its narrow genetic base due to a high degree of relatedness among released cultivars [13]. As advocated by Slater et al. [14], best linear unbiased prediction (BLUP) for selecting low heritability traits-such as tuber yield or quantitative scab resistance-may increase genetic gains, particularly when using phenotypic recurrent selection and progeny testing, or visual selection in early generations. BLUPs-a standard in animal breeding - uses pedigrees and phenotypic values of all relatives to estimate breeding values or the genetic merit for selection candidates. Trial sites from the target population of environments and years of testing may be included in BLUPs as fixed effects to improve the analysis accuracy.

The highly heterozygous tetrasomic potato shows inbreeding depression for several traits upon selfing. Its polysomic inheritance and high heterozygosity provide means for being very productive and stable across environments [15], although both make difficult crossbreeding. Tetraploid potato may show a high degree of intra- and inter-locus interactions when having four distinct alleles, thus resulting in high tuber yield [16,17]. Genomic analysis indicates, however, that tetra-allelic loci are rare in successful potato cultivars [18]. Although, recessive mutations are, noted less frequently, tetraploidy and vegetative propagation explain genetic load or accumulating recessive deleterious alleles in potato. Very recently, Zhang et al. [19] provide some insights about the genetic basis of inbreeding depression, which reduces fitness among the progeny of potato. Pericentric regions in chromosomes bear many deleterious mutations, while regions with high recombination rates carry deleterious alleles for survival and growth vigor. Such a knowledge provides means for designing potato inbred lines by removing deleterious alleles through crossbreeding.

Ploidy manipulations-scaling down with haploids and up with $2 n$ gametes the chromosome numbers [20]—offer other useful approach for broadening the genetic base on as well as for expanding Solanum germplasm utilization in potato breeding. Wild relatives and diploid landraces are genetic diversity sources captured by crossing with haploids (or sporophytes with the gametic chromosome number; i.e., $2 n=2 x=24$ chromosomes) derived from adapted tetraploid cultivars. Thereafter, haploid-species hybrids ( $2 n=2 x=24$ chromosomes) producing gametes with the sporophytic chromosome number (or $2 n$ gametes) will transmit this genetic diversity to the adapted tetraploid cultigen pool. The endosperm balance number (EBN), which is an endosperm dosage system requiring a 2:1 maternal to paternal contributions for proper seed 
development [21], ensures that only tetraploid offspring arises from sexual polyploidization through $4 x-2 x, 2 x-4 x$ and $2 x-2 x$ crossing schemes.

\section{GENOMIC RESOURCES}

In this century, potato germplasm enhancement (or pre-breeding) moved from evaluating (or phenotyping) traits in crop wild relatives or landraces into tracking genome sequences to further incorporating them into the cultigen pool [22], particularly host plant resistance and tuber quality for processing. Hence, the focus of germplasm seems to be shifting for introgression of alleles rather than traits per se, which is facilitated by using genomic resources and tools. Indeed, DNA sequencing and genetic markers allow tracking efficiently the incorporation of rare and recessive alleles. Furthermore, the use of DNA marker-aided breeding expedites transfer of major genes while reducing linkage drag. Last but not least, DNA sequences makes easy to find allelic variants for further targeting through gene editing.

The potato genome sequence was the first for an asterid and provided means for revealing 2642 genes that are specific for this angiosperm clade, e.g., those related to tuber biology [23]. The sequencing of a heterozygous diploid clone also confirms deleterious mutations are frequent and may be the basis for inbreeding depression [23]. Genome resequencing shows that potato populations may differ significantly in gene copy number [24]. Further sequencing of landraces, modern cultivars and herbarium samples reveals that potatoes grown in Europe from 1650 to 1750 were related to landraces from the South American Andes, while thereafter potatoes admixed with landraces from Chile [25]. The potatoes grown in Europe in the 19th Century had genes that seem to be involved in long-day pre-adaptation, e.g., the CYCLING DOF FACTOR1 (StCDF1) gene controlling tuberization under long days by unblocking the SELF PRUNING 6A (SP6A) pathway. The adaptive variant StCDF1 could arise de novo in Europe.

About three decades ago, Bonierbale et al. [26] put together the first potato genetic map based on restriction fragment polymorphisms (RFLPs) using a $F_{1}$ segregating population derived from crossing two heterozygous genotypes: a diploid landrace and a haploid-wild species hybrid. Synteny research revealed a high RFLP alignment with the tomato map. Since then other potato maps based on RFLPs or other DNA markers became available [27] and were used for mapping genes and quantitative trait loci [28]. Co-dominant single nucleotide polymorphism (SNP) became available as high throughput genotyping aids for potato genetic research and breeding [29]. They proved to be very useful for establishing relationships among market types [30]. Furthermore, an Infinium 12K SNP V2 Potato Array was used to determine the genetic identity of the accessions held at the gene bank of the Centro Internacional de la Papa (CIP, Lima, Perú) and to assess their genetic diversity, to establish interand intraspecific relationships among them, and to define population structure as well as hybrid origins [31]. Likewise, other Infinium 20K SNP 
array facilitated the understanding of potato breeding history by identifying "footprints" such as introgression segments plus selection and founder signatures after analyzing cultivars and breeding clones [32]. Founder effects and selection are the most significant for changing allele frequency in potato. Genetic variation located on specific chromosomal regions enabled the finding of SNPs related to host-plant resistance genes, which belong to a large highly variable gene family. Moreover, this assessment demonstrated that genetic erosion is almost absent in tetraploid potato; i.e., $96 \%$ of genetic variants found in ancestral cultivars are polymorphic in modern cultivars. DNA polymorphism analysis suggests that modern potato cultivars from Europe and North America are as diverse as the South American landraces [33]. Population structure research in a set of tetraploid cultivars (taken as a sample of 20th century potato breeding history in Europe did not reveal any distinct clustering [34]. This finding indicated that population structure was ignored when selecting the parents for potato crossbreeding. Nonetheless, population structure should be included in association genetics research to avoid any bias when modeling the DNA marker-quantitative trait relationships.

\section{ADVANCES IN METHODS AND TOOLS FOR GENETIC ANALYSIS IN A TETRASOMIC POLYPLOID}

Genetic analysis-facilitated by software and algorithms for disomic biallelic organisms - are easily used elsewhere but limited for polysomic polyploids showing multi-allelic loci. The disomic inheritance approach is, however, not easy applicable to the tetrasomic genetics of potato because of double reduction and having gametes carrying alleles identical by descent. Furthermore, multiple crossing over affect differently recombination frequency in diploids and polysomic tetraploids [35]. Although the mean frequency of crossing over may not increase, tetraploids appear having greater recombination frequency than diploids. Hence, methods and tools (including algorithms and related software) relevant for genetic analysis in tetrasomic potato became recently available online (sometimes free) for haplotype inference and epistatic detection [36,37], gene dispersal plus population structure [38], relationship matrices and kinship coefficients [39-41], genotype calling (including allele dosage from bi-allelic marker data, e.g., SNPs) [42-44], recombination fractions and haplotype phasing [45], linkage disequilibrium decay and the factors affecting it [46,47], identifying double reduction regions that increases with distances from the centromeres [48], high- or low-density linkage maps [49,50], mapping genes or quantitative trait loci (QTL) [51], and genome-wide association mapping [52]. These and other tools [53] allow getting basic knowledge on genetic architecture or insights on trait inheritance, identifying genes and QTL and tagging them to DNA markers for further use as aids for indirect selection in potato breeding, and developing models for genomic prediction of breeding values for selection. They also increase accuracy in genetic analysis due to 
its statistical power vis-à-vis available methods based on disomic inheritance, thus improving estimates relevant to achieving genetic gains while breeding tetrasomic potato.

\section{MAPPING GENES AND QUANTITATIVE TRAIT LOCI FOR DNA MARKER-AIDED BREEDING}

Tetrasomic inheritance offers the possibility of having up to five genotypes (instead of three as in disomic inheritance: $A A, A a, a a$ ) for biallelic loci; i.e., nulliplex ( $a a a a$ ), symplex (Aaaa), duplex (AAaa), triplex $(A A A a)$ and quadriplex $(A A A A)$, and these terms indicating the number of dominant alleles: from none to four, respectively. Furthermore, the two genes in the gamete of a tetrasomic polyploid may derive from different chromosomes in the zygote or identical because originate from same chromosome due to double reduction (a). This results when the sister chromatids end in same gamete owing to homologous chromosomes forming a quadrivalent and thereafter a crossing over occurring between the locus and spindle attachment. Double reduction, which depends on the distance from the centromere, causes segregation distortion in tetrasomic linkage analysis. Sir Ronald Fisher [54] provided the statistical theory of linkage in polysomic inheritance, while Luo et al. [55] gave an update for tetrasomic polyploids considering dominant and codominant markers, as well as allelic dosage, segregation distortion, mixed pairing in meiosis, and incomplete marker phenotype data. Bourke et al. [56] described further an approach for developing genetic linkage maps with large number of markers in a tetrasomic species, and validated it using data from a $F_{1}$ segregating population of tetraploid potato, whose 235 individuals were genotyped with a 20K SNP array and after converting SNP intensity values to allele dosages. The resulting potato linkage map included 6910 markers across the 12 potato chromosomes and with a total length of $1061 \mathrm{cM}$. The use of mono-parental parthenogenetic haploids derived from tetraploid cultivars after prickle pollination with the diploid S. tuberosum Group Andigenum (Phureja), permits also mapping genes and quantitative trait loci with single-dose markers in potato, as demonstrated recently [57]. The total length of these genetic maps was $2675.6 \mathrm{cM}$ and having on average 55.24 SNPs per linkage group.

Throughout the 1990s genetic maps based on low throughput DNA markers, isozymes and genes controlling morphological traits became available for diploid potatoes [58]. Host plant resistance genes (particularly for cyst nematode, late blight and viruses), tuber traits (skin color, shape) and flower color were among the traits included. Linkages maps based on SNPs from two diploid populations were further put together to validate the assembled potato genome sequence [59] and the functionality of an Infinium Potato Array. These maps included 4400 markers and covering up to $88 \%$ of the genome sequence. $\mathrm{A} \mathrm{F}_{2}$ segregating population derived from crossing two potato diploid inbred lines were also used for genetic mapping of tuber color (skin and flesh), pigment, 
shape and length/width ratio; eye tubers (from where sprouts grow); "jelly end" (related to high concentration of reducing sugars and low starch content, and producing tubers instead of sprouts at the eyes of tubers), and anther development [60]. Other alike $\mathrm{F}_{2}$ offspring facilitated recently the mapping of QTL for tuber quality traits (shape plus flesh and skin color) [61]. The use of $F_{2}$ or recombinant populations derived from inbred lines likely allows a precise major gene location and increases the resolution of QTL mapping.

Tetraploid segregating offspring were used along with software for linkage analysis in tetrasomic species [62] for mapping flower color, foliage maturity, plus tuber traits such as skin texture, specific gravity (SG), dry matter content (DMC) and yield in potato [63]. An interesting finding was to identify different QTL that did not co-locate for DMC ad SG, which are strongly correlated. Research in other tetraploid populations led to identifying 41 QTL for high value traits such as fried chip color (after 5.5$7.2^{\circ} \mathrm{C}$ storage), as well as tuber yield, number per plant, weight and size [64]. It is worth noting that a QTL for tuber weight, length, and width colocalized with a QTL for foliage maturity on chromosome 5. Progeny derived from crossing a susceptible cultivar and a resistant breeding clone (both tetraploids) were genotyped with an Infinium SNP array and phenotyped for internal heat necrosis [65]. Significant QTL accounting $28.21 \%$ and $25.3 \%$ of the variation for incidence and severity, respectively, were found on chromosomes 1, 5, 9, and 12. Very recently, the genetic analysis of a tetraploid segregating $F_{1}$ offspring facilitated the mapping of a host plant resistance gene to cyst nematode derived from the wild diploid species S. multidissectum at the distal end in the short arm of chromosome 5 [66]. These and other alike research provide insights on the genetics of target traits and may allow finding interesting high throughput DNA markers that should undergo further testing to demonstrate their suitability for aided breeding through indirect selection in potato.

There are various resistance $(R)$ genes that co-evolved with $P$. infestans in central Mexico-its center of origin and provide high levels of racespecific resistance. The proteins coded by $R$ genes target the avirulence (AVR) proteins that are included among the RXLR class effectors secreted by the pathogen [67]. The availability of genome-wide catalogs of these effectors accelerate the cloning of $R$ genes and assist on their deployment while monitoring the pathogen strains. For example, eight $R 2$ gene homologs (with specific response to AVR2) were cloned in the Swedish potato breeding clone SW 93-1015 [68], whose genotype is simplex for this trait. Resistance gene enrichment and sequencing allows finding and annotating pathogen resistance gene in the plant genome [69], thus paving the way for developing co-segregating DNA markers for target trait or accelerating the cloning of $R$ genes from Solanum species that belong to the NB-LRR type.

Various research articles about host plant resistance QTL for late blight are available since the 1990s. They often relate to late foliage maturity and 
are based on phenotyping the disease development in potato. A dynamic phenotyping approach at consecutive time points during disease development (that reflects genes functioning at different stages during the host plant-pathogen interaction) was able to identify six QTL (one each on chromosomes 2, 7 and 12 plus three on chromosome 9), while only one QTL was found using the former [70]. This approach may allow targeting genes or QTL for developing DNA markers for aided breeding. The gene Rpi-phu1 gene, which derives from diploid species of $S$. tuberosum Group Andigenum and proximal to marker allele GP94 ${ }_{250}$, provides a high level of host plant resistance to late blight in potato and it appear to be very suitable for marker-aided selection in diploid and tetraploid potatoes [71]. Likewise, a polymerase chain reaction-based DNA marker serves for tracking and selecting $R B$ gene from the wild related species $S$. bulbocastanum [72], which gives broad spectrum, high level of host plant partial resistance to late blight and to which different strains of $P$. infestans are uncapable to overcome quickly [73]. Resistance QTL may be further related to the potato reference genome, in which major nucleotide binding, leucine-rich-repeat (NB-LRR) resistance genes (often from wild species) are known. For example, broad-spectrum, durable, field resistance provided by QTL dPI09c is due to the NB-LRR gene R8 [74], which recognizes Avr8 and is homologous to the NB-LRR protein Sw-5 found in tomato, as shown recently [75]. The EU cultivar "Sarpo Mira", along with US cultivars "Jacqueline Lee" and "Misaukee" and cultivars PB06 and S-60 from China, carry this $R 8$ gene, thus showing its worldwide use in potato breeding. Pyramiding host plant resistance genes is the best strategy to achieve durable host plant resistance to late blight, thus increasing the lifespan of potato cultivars bearing them.

Association or linkage disequilibrium mapping seeks relationships between genotypes and phenotypes in a set of individuals rather than using biparental crossing to generate a family with known relatednessthus, sampling only few alleles of the species-although both are complementary [76]. D'Hoop et al. [77] suggest, after phenotypic analysis, that results from a single-year balanced field trial along with breeders' records (across sites and over years) provides suitable data for a genome wide association study (GWAS). Mixed-model association mapping considering a kinship matrix seems to be very appropriate for detecting QTL in potato [78]. Really, GWAS allows identifying genomic regions or genes that are very relevant for breeding this crop, e.g., host plant resistance to pathogens [79-85], foliage maturity [79], chip quality plus tuber starch content and yield [86-88], other tuber quality traits [52,89] and marketable tuber yield plus size and number under drought [90]. This association mapping research provided insights in the genetics of various characteristics and led to identifying suitable diagnostic DNA markers for indirect aided selection of target breeding traits in potato (Table 1). A R package based on the $\mathrm{Q}+\mathrm{K}$ mixed model—known as GWASpoly-has facilitated genome wide association research in polysomic polyploids such 
as potato [52]. This software allows modeling various types of polysomic gene action, such as additive as well as simplex and duplex dominant. Its further use also indicated that DNA marker density and population size may limit association mapping in tetrasomic potato. The marker density should indeed surpass the linkage disequilibrium decay for GWAS. Sound experimental design (e.g., incomplete blocks with a minimum of three replicates) for multi-site testing over years or cropping seasons allows adequate field phenotyping of quantitative characteristics, which are often affected by the genotype $\times$ environment interaction. Selecting germplasm that maximize diversity and with appropriate relatedness levels will be also key in association genetics. These factors along with high-throughput dense DNA markers, such as SNPs, determine the power for identifying QTL in potato.

A non-statistical alternative method for discovering genes is graphical genotyping [91], which visualizes haplotype sharing in association panels among individuals that also share the same locus, as well as facilitates noticing the linkage drag of introgression segments in breeding populations [92]. Genotype-by-sequencing also provide means for identifying with accuracy genes under selection in the highly heterozygous tetrasomic potato cultivars [93].

Table 1. Genome-wide association study examples in potato.

\begin{tabular}{|l|l|c|}
\hline Characteristic & Most Important Finding(s) in Reference Population & References \\
\hline \multirow{5}{*}{$\begin{array}{l}\text { Host plant } \\
\text { resistance to late } \\
\text { blight and plant } \\
\text { maturity }\end{array}$} & $\begin{array}{l}\text { Highly significant quantitative trait loci (QTL) related to PCR-based } \\
\text { flanking the } \text { R1 locus at 0.2 cM in tetraploid cultivars from America } \\
\text { (North and South), Asia and Europe bred between 1850 and 1993 }\end{array}$ & [79] \\
\cline { 2 - 3 } & $\begin{array}{l}\text { a single nucleotide polymorphisms (SNPs) significantly associated } \\
\text { aith maturity corrected resistance (MCR) and accounting for 50\% of } \\
\text { involved in defense signaling) }\end{array}$ & [82] \\
\cline { 2 - 4 } & $\begin{array}{l}\text { 27 SNPs with significant association with MCR related to strong } \\
\text { candidate genes for quantitative resistance in German breeding } \\
\text { clones according to functional annotation (being most important: a } \\
\text { lipoxygenase (jasmonate pathway), a 3-hydroxy-3-methylglutaryl } \\
\text { coenzyme A reductase (mevalonate pathway), a P450 protein } \\
\text { (terpene biosynthesis), a transcription factor and a homolog of a } \\
\text { major gene for resistance from diploid Solanum venturii) }\end{array}$ & [83] \\
\hline
\end{tabular}


Table 1. Cont.

\begin{tabular}{|c|c|c|}
\hline Characteristic & Most Important Finding(s) in Reference Population & References \\
\hline \multirow{3}{*}{$\begin{array}{l}\text { Host plant } \\
\text { resistance to late } \\
\text { blight }\end{array}$} & $\begin{array}{l}\text { Two nucleotide binding-site markers targeting resistance-analog } \\
\text { genes with potential for aided-selection in Dutch cultivars }\end{array}$ & {$[80]$} \\
\hline & $\begin{array}{l}16 \text { organ-specific QTL (6 for leaf resistance and } 10 \text { for stem } \\
\text { resistance, respectively) accounting between } 13.7 \% \text { and } 50.9 \% \text { of the } \\
\text { phenotypic variance in diploid S. tuberosum Group Phureja ( } 11 \\
\text { candidate genes out of } 16 \text { QTL coding for diverse proteins including } \\
\text { a leucine-rich repeat kinase) }\end{array}$ & [84] \\
\hline & $\begin{array}{l}\text { SNP on chromosome } 9 \text { significantly associated but linked to } \\
\text { instability in a tropical highland breeding population; i.e., AACC or } \\
\text { AAAC highly resistant in some sites, while AAAA moderate stable } \\
\text { resistance across sites }\end{array}$ & [85] \\
\hline $\begin{array}{l}\text { Verticillium wilt } \\
\text { resistance }\end{array}$ & $\begin{array}{l}\text { Allele of the STM1051 marker accounts }>10 \% \text { and } 25 \% \text { of the } \\
\text { phenotypic variation in two sub-populations based on co-ancestry of } \\
\text { tetraploid North American cultivars }\end{array}$ & [81] \\
\hline \multirow[b]{2}{*}{$\begin{array}{l}\text { Tuber quality } \\
\text { traits }\end{array}$} & $\begin{array}{l}69 \text { significant amplified fragment length polymorphisms associated } \\
\text { to } 11 \text { traits throughout the genome of a subset of worldwide } \\
\text { available germplasm, thus showing the potential for association } \\
\text { mapping using available phenotypic data, modest number of DNA } \\
\text { markers, and relatively simple statistical analysis }\end{array}$ & [89] \\
\hline & $\begin{array}{l}\text { Robust and significant associations between DNA variants and } \\
\text { genes encoding enzymes participating in starch and sugar } \\
\text { metabolism or transport in German tetraploid cultivars and } \\
\text { breeding clones } \\
\text { User-friendly PCR assays for specific candidate gene alleles useful } \\
\text { for marker-aided selection of chip quality after cold storage and } \\
\text { tuber starch content }\end{array}$ & {$[87,88]$} \\
\hline $\begin{array}{l}\text { Tuber cold } \\
\text { sweetening }\end{array}$ & $\begin{array}{l}\text { Leucine aminopeptidase role in natural quantitative variation of } \\
\text { tuber starch and sugar content and their interconversion in } \\
\text { tetraploid German cultivars and breeding clone }\end{array}$ & [86] \\
\hline $\begin{array}{l}\text { Tuber shape and } \\
\text { eye depth }\end{array}$ & $\begin{array}{l}\text { Significant QTL for both tuber shape and eye depth on } \\
\text { chromosome } 10\end{array}$ & [52] \\
\hline $\begin{array}{l}\text { Tuber number, } \\
\text { size and weight } \\
\text { under drought } \\
\text { stress }\end{array}$ & $\begin{array}{l}\text { Significant SNP-tuber trait associations in region of chromosome } 3 \\
\text { for European tetraploid cultivars }\end{array}$ & [90] \\
\hline
\end{tabular}

\section{GENOMIC PREDICTION OF BREEDING VALUES FOR FURTHER USE IN SELECTION}

Genomic selection (GS) relying on estimated breeding values (GEBV) offers an approach that increases efficiency and accelerates breeding [94]. GS captures the simultaneous effects of dense DNA markers spread throughout the genome, and it allows predicting breeding values assuming linkage disequilibrium among trait polymorphisms and 
markers. A training set from the population (TP) is used for genotyping and phenotyping with the aim of getting GEBV using statistical modeling. Thereafter, the GEBV are used to predict the worth of individuals from a breeding population (BP), in which they are only genotyped but not phenotyped.

In polysomic polyploids accounting for allele dosage (i.e., the additive effect of multiple copies of same allele) may improve prediction accuracy [95,96], thus increasing genetic gains from GS, particularly when a large number of genes with small individual effects affect target breeding trait(s). Polyploidy, heterozygosity, linkage disequilibrium decay, marker number, reference population plus its effective size (that should consider the high allelic diversity due to polyploidy), and trait heritability also influence in tetrasomic potato the accuracy of GS [97], whose genetic gains appears to be above those of pedigree or phenotypic selection. Sverrisdóttir et al. [98] further indicated that combining additively genomic prediction models across TP may yield high quality GEBVs that could be relevant for GS in related BP.

Genomic prediction models for selection became available in various potato breeding populations and for several traits such as starch content [99,100] and yield [99], tuber DMC or SG [96,98,101], chipping quality determined by the fry color $[96,98,99]$, total tuber yield and its components such as number and size [96,100,101], tuber flesh color [101], stems per plant [101] and host plant resistance to late blight [100,102] and common scab [102] (Table 2 gives details for each of these traits). Such encouraging results show that GS based on GEBV may become a feasible breeding approach in tetrasomic potato. It worth highlighting that GS accuracy, as noted in some of the above cited research, relates directly to trait heritability that may be low due to significant non-additive genetic effects [103]. Hence, including these non-additive (dominance and epistatic) effects may improve the genome-wide prediction accuracy, particularly when using it for selecting low-heritability traits in early clonal generations. In this regard, Bradshaw [104] proposed an approach for integrating GS for quantitative traits within the most promising offspring. In this approach, seedlings of each of the best hybrid progeny are grown in the greenhouse, and in the following year planting as TP a sample of them in replicated small field plots (e.g., 10 plants) for assessing traits in the target environment to avoid genotype $\times$ environment interactions. The remaining breeding clones (BP) will undergo GS, thus reducing the time and costs of field testing for selecting parents for the next cycle crossing cycle or identifying promising bred germplasm for potential cultivar releases. 
Table 2. Summary of recent research findings on genomic prediction of breeding values in potato.

\begin{tabular}{|c|c|c|}
\hline Trait & Main Output(s) in Reference Population & References \\
\hline \multirow[b]{2}{*}{$\begin{array}{l}\text { Host plant resistance } \\
\text { to late blight }\end{array}$} & $\begin{array}{l}\text { Prediction accuracy ca. } 0.8 \text {, irrespective of model, for maturity } \\
\text { corrected resistance in tetraploid German breeding clones }\end{array}$ & [100] \\
\hline & $\begin{array}{l}\text { Genomic heritability of } 0.46 \pm 0.04 \text { with estimated prediction } \\
\text { correlation of ca. } 0.31 \text { in advanced US tetraploid breeding } \\
\text { clones }\end{array}$ & [102] \\
\hline $\begin{array}{l}\text { Host plant resistance } \\
\text { to common scab }\end{array}$ & $\begin{array}{l}\text { Genomic heritability of } 0.45 \pm 0.02 \text { with estimated prediction } \\
\text { correlation of ca. } 0.27-0.31 \text { in advanced US tetraploid breeding } \\
\text { clones }\end{array}$ & [102] \\
\hline Tuber flesh color & $\begin{array}{l}\text { Prediction accuracy (after cross validation) above or equal to } 0.7 \\
\text { except when using Bayes C ( } 0.59 \text { ) in European cultivars }\end{array}$ & [101] \\
\hline \multirow[t]{2}{*}{ Starch content } & $\begin{array}{l}\text { Cross-prediction validation correlation of } 0.56 \text { in training panel } \\
\text { but between } 0.30 \text { and } 0.31 \text { in test panel derived from tetraploid } \\
\text { mapping population of breeding program in Denmark }\end{array}$ & [99] \\
\hline & $\begin{array}{l}\text { Prediction accuracy increasing by } 8 \% \text { if model includes additive } \\
\text { and dominance effects rather than only additive effects in } \\
\text { tetraploid German breeding clones }\end{array}$ & [100] \\
\hline \multirow{3}{*}{$\begin{array}{l}\text { Tuber dry matter or } \\
\text { specific gravity }\end{array}$} & $\begin{array}{l}\text { SNPs captured } 20 \% \text { of additive genetic variance of the } \\
\text { total genetic variance; prediction accuracy ranging between } \\
0.25 \text { and } 0.63 \text { in unselected } \text { US }_{1} \text { tetraploid breeding population }\end{array}$ & [96] \\
\hline & $\begin{array}{l}\text { Cross-prediction validation correlations ranged from } 0.75 \text { to } 0.83 \\
\text { when combining tetraploid mapping populations of breeding } \\
\text { program in Denmark but ranging between } 0.37 \text { and } 0.71 \text { when } \\
\text { predicting across populations }\end{array}$ & [98] \\
\hline & $\begin{array}{l}\text { Average prediction accuracy (cross-validation) across models of } \\
0.65(0.54-0.68) \text { in European cultivars }\end{array}$ & [101] \\
\hline \multirow{3}{*}{$\begin{array}{l}\text { Frying chipping } \\
\text { quality }\end{array}$} & $\begin{array}{l}\text { SNPs captured } 45 \% \text { of additive genetic variance of the } \\
\text { total genetic variance; prediction accuracy ranging between } 0.4 \\
\text { and } 0.45 \text { when using different pedigree depth in unselected US } \\
F_{1} \text { tetraploid breeding population }\end{array}$ & [96] \\
\hline & $\begin{array}{l}\text { Cross-prediction validation correlations ranged from } 0.39 \text { to } 0.79 \\
\text { when combining tetraploid mapping populations of breeding } \\
\text { program in Denmark but ranging between } 0.28 \text { and } 0.48 \text { when } \\
\text { predicting across populations }\end{array}$ & [98] \\
\hline & $\begin{array}{l}\text { Cross-prediction validation correlation of } 0.73 \text { in training panel } \\
\text { but between } 0.42 \text { and } 0.43 \text { in test panel from tetraploid mapping } \\
\text { population of breeding program in Denmark }\end{array}$ & [99] \\
\hline $\begin{array}{l}\text { Stem number per } \\
\text { plant }\end{array}$ & $\begin{array}{l}\text { Average prediction accuracy (cross-validation) across models of } \\
0.05(0.01-0.13) \text { in European cultivars }\end{array}$ & {$[101]$} \\
\hline
\end{tabular}


Table 2. Cont.

\begin{tabular}{|l|l|c|}
\hline Trait & Main Output(s) in Reference Population & References \\
\hline \multirow{5}{*}{$\begin{array}{l}\text { Tuber yield and } \\
\text { components }\end{array}$} & $\begin{array}{l}\text { SNPs captured 45\% of additive genetic variance of the } \\
\text { total genetic variance; prediction accuracy ranging between } \\
0.06 \text { and 0.63 in unselected US F tetraploid breeding population }\end{array}$ & \\
\cline { 2 - 3 } & $\begin{array}{l}\text { 8\% increase in prediction model accuracy when using both } \\
\text { additive and dominance effects instead of additive effects only } \\
\text { in tetraploid German breeding clones }\end{array}$ & \\
\cline { 2 - 3 } & $\begin{array}{l}\text { Average prediction accuracy (cross-validation) across models of } \\
0.37 \text { (0.22-0.41), 0.32 (0.15-0.41), and 0.17 (0.13-0.23) for total } \\
\text { yield, size (as measured by diameter) and number, respectively, } \\
\text { in European cultivars }\end{array}$ & \\
\hline
\end{tabular}

\section{OUTLOOK: REWRITING THE POTATO BREEDER'S EQUATION}

Potato breeding has been using mostly a phenotypic recurrent selection approach across generations and selecting therein promising clones for further cultivar releases. Slater et al. [105] noticed that marker-aided selection (MAS) appears to be cost-effective, particularly for quantitative traits. Furthermore, they indicated that using MAS along with estimated breeding values may reduce the breeding cycle from 10 to 4 years, while GS will bring it down to 1 year (by selecting early and intensely in the first seedling generation rather than waiting for field testing), thus accelerating genetic gains significantly. Likewise, high throughput phenotyping (HTP) with imaging sensors in greenhouses and unmanned aerial vehicles with sensors for field phenotyping will both reduce cost-effectively the breeding cycle and offer means for breeding potatoes differently. Largescale phenotyping will also improve GS accuracy. For example, infrared thermography provides an easy, fast and non-destructive method for tuber yield when potatoes are grown under plentiful moisture [106], while near-infrared reflection spectroscopy may be used for predicting crude protein and dry matter contents in potato tubers [107].

Although, as reiterated recently [108], DNA markers linked to target traits assists potato germplasm enhancement while introgressing genes or incorporating genetic resources from crop wild relatives or landraces, speeding up gains by reducing the breeding cycle remains a key goal. In this regard, producing potatoes from true seed-propagated $F_{1}$ diploid hybrids after crossing inbred diploid lines are being pursued both in Europe [109] and North America [110], and its great potential already shown in East Africa [111]. This breeding approach brings a new step in the evolution of potato breeding; i.e., crop re-domestication by returning to diploidy for implementing an inbred line strategy that reduces genetic load through inbreeding and thereafter combines target traits through hybridization [112]. Marker-aided backcrossing may be further used for introducing desired genes from other potato germplasm (e.g., host plant resistance or tuber quality) into elite diploid inbred lines. However, a 
gametophytic self-incompatibility system makes difficult developing inbred lines in diploid potatoes. Nonetheless, the use of the dominant $S$ locus inhibitor (Sli) allele-found in S. chacoense-beats this hurdle [113]. Moreover, gene editing using CRISPR/Cas 9 has been shown to knock out the self-incompatibility gene $S$-RNase, thus facilitating inbreeding in diploid potato [114]. Likewise, some haploids derived from tetraploid potatoes may be both self-compatible and male fertile, thus allowing selfing. It is worth noting that recessive allele frequency changes owing to selection may be faster at the diploid than at the tetraploid level because the recessive allele is only hidden by the heterozygous in the diploids whereas simplex, duplex and triplex include it in the tetraploids. In theory, $s q^{2}$ individuals having a recessive genotype will be selected in a large diploid breeding population with $q$ being the allele frequency and $s$ the intensity of selection, while $s q^{4}$ denotes the fraction of recessive genotypes selected in a large tetraploid breeding population. Hence, diploid improvement offers new routes to accelerate and increase genetic gains in potato breeding because overcomes inherent barriers due to ploidy, outcrossing and heterozygosity of this crop [115]. Furthermore, $\mathrm{F}_{1}$ trueseed propagated hybrids will avoid accumulating pathogens in and physiological decline of potato tubers, which have also a high storage and transport costs.

Clustered regularly interspaced short palindromic repeats and CRISPRassociated protein-9 (CRISPR-Cas9) offers means for gene editing in potato, as shown elsewhere [116]. Gene editing using tetraploid potato protoplast may lead to mutations in the four alleles in a single transfection [117]. Desired traits to pursue are, inter alia, related to starch quality, reduced glycoalkaloids, regulating enzymatic darkening process, resisting blackspot bruising, having less asparagine that change into acrylamide after frying, or host plant resistance to pathogens and pests. Gene editing can also used for targeted improvement through promoting alleles in a potato breeding population, thus accelerating and increasing genetic gains $\left(\Delta_{G}\right)$-which lead to rewriting its equation as follows:

$$
\Delta_{\mathrm{G}}=\frac{a i \sigma^{2}}{t}+\text { gene editing for promoting desired alleles }
$$

where $a, i, \sigma^{2}$ and $t$ are accuracy that may improve due to HTP, selection intensity by increasing the effective population size using early testing coupled with GS, genetic variation for target trait(s) that may be enhanced by incorporating useful exotic germplasm, and time spent in each cycle through speed breeding, respectively. Combining marker-aided selection and estimating breeding values may further improve potato breeding efficiency by significantly reducing the cycle length to identify promising germplasm.

Considering the genetic enhancement research advances and new breeding techniques or tools as described in previous paragraphs, a new approach for population improvement and cultivar development may be envisaged (Figure 1). In this approach, (maternal) haploids are extracted 
from elite tetraploid breeding cultivars, and thereafter included in crossing blocks with exotic (crop wild relatives or landrace) diploid germplasm for base broadening or introgression of desired gene(s). Further diploid or tetraploid genomic recurrent selection within each defined heterotic group leads to diverse and improved breeding populations at each ploidy level. Although ploidy manipulations offer means for introgressing and incorporating genetic resources from wild relatives in potato breeding, obtaining large segregating tetraploid populations through sexual polyploidization with $2 n$ gametes often remains as a challenge. Such a limitation must be overcome as well as pursuing "nobilization" through backcrossing to the cultigen pool to eliminate most of the linkage drag from the wild species genome. Interpopulation genomic reciprocal recurrent selection allows diploid inbred line development for further crossing and producing $F_{1}$ hybrids. Likewise, crossing blocks considering heterotic groups and estimated breeding values result in tetraploid hybrid seed that is used for clonal breeding in cultivar development. Gene editing in the elite bred germplasm may be pursued for promoting alleles controlling desired traits and missing in the breeding populations.

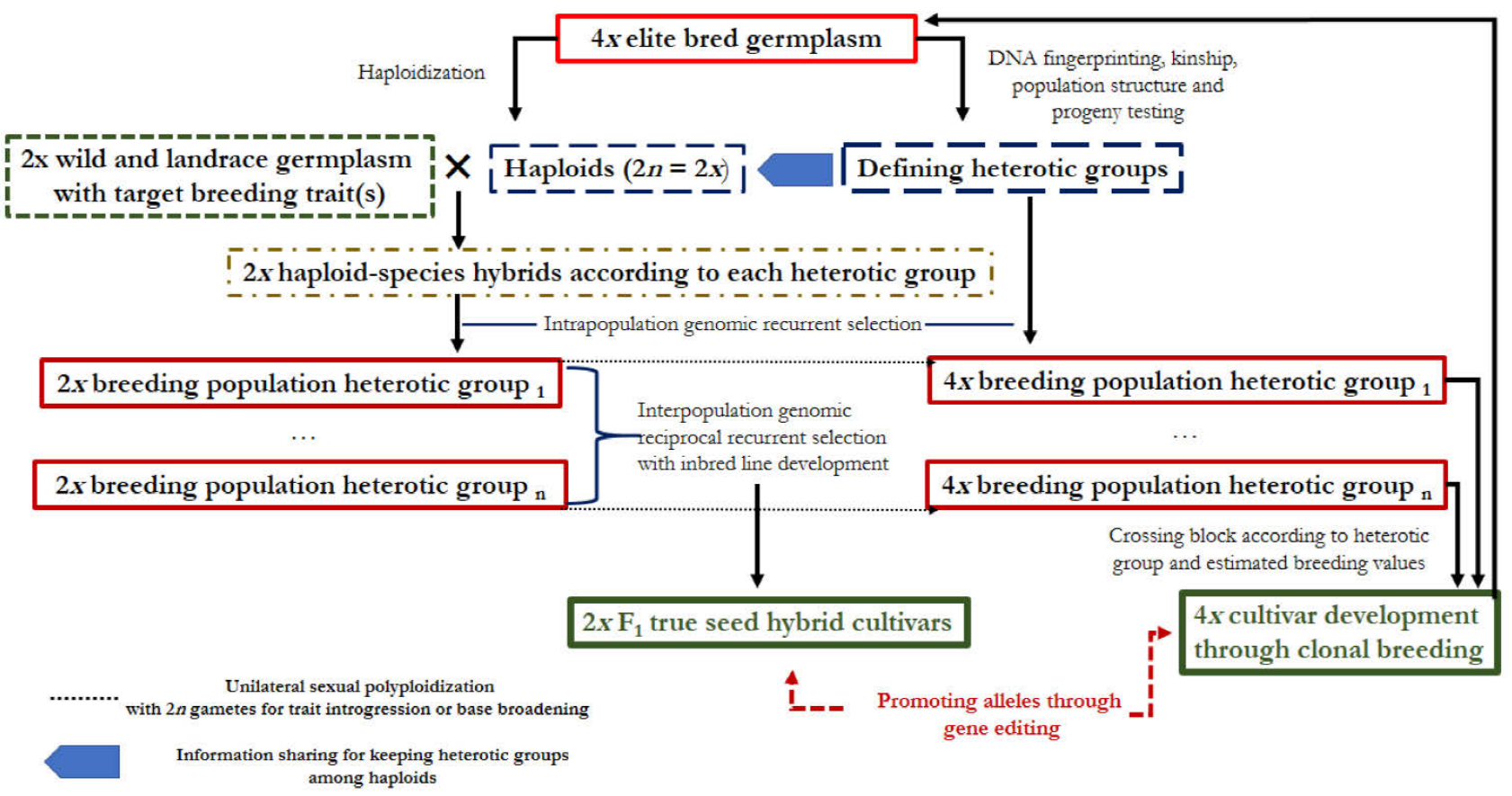

Figure 1. Diagram showing an interploidy breeding approach for population improvement and cultivar development in potato.

\section{ACKNOWLEDGEMENTS}

The author thanks grant and other funding provided for Sveriges potatisförädling at the Swedish University of Agricultural Sciences (SLU) from the Swedish Research Council Formas for both Sveriges potatisförädling (since 2011) and project Genomisk prediktion $i$ 
kombination med högkapacitetsfenotypning för att öka potatisens knölskörd $i$ ett föränderligt klimat (2020-2022), Stiftelsen för miljöstrategisk forskning (Mistra) and SLU through the Mistra Biotech project (2012-2020), Stiftelsen Lantbruksforskning (SLF) for Development of late blight resistant food potatoes for large parts of Sweden project (20162019), Forskningsrådet (Norway) for Integrating Machine Learning and Genomic Prediction for Advancing Norwegian Potato Cultivar Development, and SLU.

\section{REFERENCES}

1. van Merrienboer S. World potato map 2019: fries are on the menu globally. Amsterdam (The Netherlands): RaboResearch Food \& Agribusiness; 2019.

2. Spooner DM, McLean K, Ramsay G, Waugh R, Bryan GJ. A single domestication for potato based on multilocus amplified fragment length polymorphism genotyping. Proc Natl Acad Sci U S A. 2005;102:14694-9.

3. Earle R. A brief history of that most noble tuber, the potato. 2019. Available from: https://lithub.com/a-brief-history-of-that-most-noble-tuber-the-potato/. Accessed 2019 Apr 1.

4. Hardigan MA, Laimbeer FPE, Newton L, Crisovan E, Hamilton JP, Vaillancourt B, et al. Genome diversity of tuber-bearing Solanum uncovers complex evolutionary history and targets of domestication in the cultivated potato. Proc Natl Acad Sci U S A. 2017;114(46):E9999-10008. doi: 10.1073/pnas.1714380114

5. Glendinning DR. Potato introductions and breeding up to the early 20th century. New Phytol. 1983;94:479-505.

6. van Berloo R, Hutten RCB, van Eck HJ, Visser RGF. An online potato pedigree database resource. Potato Res. 2007;50:45-57.

7. Li X, Xu J, Duan S, Bian C, Hu J, Shen H, et al. Pedigree-based deciphering of genome-wide conserved patterns in an elite potato parental line. Front Plant Sci. 2018;9:690. doi: 10.3389/fpls.2018.00690

8. Endelman JB, Schmitz Carley CA, Douches DS, Coombs JJ, Bizimungu B, De Jong WS, et al. Pedigree reconstruction with genome-wide Markers in potato. Am J Potato Res. 2017;94:184-90.

9. Andrivon D. Potato facing global challenges: how, how much, how well? Potato Res. 2017;60(3-4):389-400. doi: 10.1007/s11540-018-9386-z

10. Ortiz R, Mihovilovich E. Genetics and cytogenetics in potato. In: Campos H, Ortiz O, editors. The Potato Crop. Cham (Switzerland): Springer; 2020. p. 21947.

11. Douches DS, Maas D, Jastrzebski K, Chase RW. Assessment of potato breeding progress in the USA over the last century. Crop Sci. 1996;36:1544-52.

12. Jansky S. Breeding for disease resistance in potato. Plant Breed Rev. 2000;19:69-155.

13. Mendoza HA, Haynes FL. Genetic relationship among potato cultivars grown in the United States. HortScience. 1974;9:328-30. 
14. Slater AT, Wilson GM, Cogan NOI, Forster JW, Hayes BJ. Improving the analysis of low heritability complex traits for enhanced genetic gain in potato. Theor Appl Genet. 2014;127:809-20.

15. Muthoni J, Kabira J, Shimelis H, Melis R. Tetrasomic inheritance in cultivated potato and implications in conventional breeding. Austr J Crop Sci. 2015;9:185-90.

16. Mendoza HA, Haynes FL. Genetic basis of heterosis for yield in the autotetraploid potato. Theor Appl Genet. 1974;45:21-5.

17. Mendiburu AO, Peloquin SJ. The significance of $2 \mathrm{~N}$ gametes in potato breeding. Theor Appl Genet. 1977;49:53-61.

18. Bonierbale MW, Plaisted RL, Tanksley SD. A test of the maximum heterozygosity hypothesis using molecular markers in tetraploid potatoes. Theor Appl Genet. 1993;86:481-91.

19. Zhang C, Wang P, Tang D, Yang Z, Lu F, Qi J, et al. The genetic basis of inbreeding depression in potato. Nat Genet. 2019;51:374-8.

20. Ortiz R, Simon P, Jansky S, Stelly D. Ploidy manipulation of the gametophyte, endosperm, and sporophyte in nature and for crop improvement-A tribute to Prof. Stanley J. Peloquin (1921-2008). Ann Bot. 2009;104:795-807.

21. Ehlenfeldt MK, Ortiz R. On the origins of endosperm dosage requirements in Solanum and other angiosperma genera. Sexual Plant Repr. 1995;8:189-96.

22. Bethke PC, Halterman DA, Jansky SH: Potato germplasm enhancement enters the genomics era. Agronomy. 2019;9:575. doi: 10.3390/agronomy9100575

23. The Potato Genome Sequencing Consortium. Genome sequence and analysis of the tuber crop potato. Nature. 2011;475:189-95.

24. Gálvez JH, Tai HH, Barkley NA, Gardner K, Ellis D, Strömvik MV. Understanding potato with the help of genomics. AIMS Agric Food. 2017;2:1639.

25. Gutaker RM, Weiß CL, Ellis D, Anglin NL, Knapp S, Fernández-Alonso JL, et al. The origins and adaptation of European potatoes reconstructed from historical genomes. Nat Ecol Evol. 2019;3:1093-101.

26. Bonierbale MW, Plaisted RL, Tanksley SD, RFLP maps based on a common set of clones reveal modes of chromosomal evolution in potato and tomato. Genetics. 1988;120:1095-103.

27. Meyer S, Nagel A, Gebhardt C. PoMaMo-a comprehensive database for potato genome data. Nucleic Acids Res. 2005;33:D666-70.

28. Watanabe K. Potato genetics, genomics and applications. Breed Sci. 2015;65:53-68.

29. Anithakumari AM, Tang J, van Eck HJ, Visser RGF, Leunissen JAM, Vosman B, et al. A pipeline for high throughput detection and mapping of SNP from EST databases. Mol Breed. 2010;26:65-75.

30. Hamilton JP, Hansey CN, Whitty BR, Stoffel K, Massa AN, Van Deynze A, et al. Single nucleotide polymorphism discovery in elite North American potato germplasm. BMC Genomics. 2011;12:302. doi: 10.1186/1471-2164-12-302 
31. Ellis D, Chavez O, Coombs J, Soto J, Gomez R, Douches D, et al. Application of the SolCAP 12K SNP array in fingerprinting and diversity analysis in the global in trust potato collection. Genome. 2018;61:523-37.

32. Vos PG, Uitdewilligen JGAML, Voorrips RE, Visser RGF, van Eck HJ. Development and analysis of 20k SNP array for potato (Solanum tuberosum): an insight into the breeding history. Theor Appl Genet. 2015;128:2387-401.

33. D’hoop BB, Paulo MJ, Kowitwanich K, Sengers M, Visser RGF, van Eck HJ, et al. Population structure and linkage disequilibrium unraveled in tetraploid potato. Theor Appl Genet. 2010;121:1151-70.

34. Stich B, Urbany C, Hoffman P, Gebhardt C. Population structure and linkage disequilibrium in diploid and tetraploid potato revealed by genome-wide high-density genotyping using the SolCAP SNP array. Plant Breed. 2013;132:718-24.

35. Sved JA. The relationship between diploid and tetraploid recombination frequencies. Heredity. 1964;19:585-96.

36. Motazedi E, de Ridder D, Finkers R, Baldwin S, Thomson S, Monaghan K, et al. TriPoly: a haplotype estimation for polyploids using sequencing data of related individuals. Bioinformatics. 2018;34:3864-72.

37. Shen J, Li Z, Chen J, Song Z, Zhou Z, Shi Y. SHEsisPlus, a toolset for genetic studies on polyploid species. Sci Rep. 2016;6:24095. doi: 10.1038/srep24095

38. Field DL, Broadhurst LM, Elliott CP, Young AG. Population assignment in autopolyploids. Heredity. 2017;109:389-401.

39. Amadeu RR, Cellon C, Olmstead JW, Garcia AFF, Resende MFR Jr, Muñoz PR. AGHmatrix: R package to construct relationship matrices for autotetraploid and diploid species: a blueberry example. Plant Genome. 2016;9:1-10. doi: 10.3835/plantgenome2016.01.0009

40. Hamilton MG, Ker RJ. Computation of the inverse additive relationship matrix for autopolyploid and multiple-ploidy populations. Theor Appl Genet. 2018;131:851-60.

41. err RJ, Li L, Tier B, Dutkowski GW, McRae TA. Use of the numerator relationship matrix in genetic analysis of autopolyploid species. Theor Appl Genet. 2012;124:1271-82.

42. Faria SR. Genotipagem de polyplôides: um modelo de urnas e bolas [PhD thesis]. São Paulo (Brazil): Instituto de Matemática e Estatística, Universidade São Paulo; 2012.

43. Schmitz Carley CA, Coombs JJ, Douches DS, Bethke PC, Palta JP, Novy RG, et al. Automated tetraploid genotype calling by hierarchical clustering. Theor Appl Genet. 2017;130:717-26.

44. Voorrips RE, Gort G, Vosman B. Genotype calling in tetraploid species from biallelic marker data using mixture models. BMC Bioinf. 2011;12:172. doi: 10.1186/1471-2105-12-172

45. Mollinari M, Garcia AAF. Linkage analysis and haplotype phasing in experimental autopolyploid populations with high ploidy level using hidden Markov models. G3. 2019;9:3297-314. doi: 10.1534/g3.119.400378 
46. Simko I, Haynes KG, Jones RW. Assessment of linkage disequilibrium in potato genome with single nucleotide polymorphism markers. Genetics. 2006;173:2237-45.

47. Vos PG, Paulo MJ, Voorrips RE, Visser RGF, van Eck HJ, van Eeuwijk FA. Evaluation of LD decay and various LD-decay estimators in simulated and SNP-array data of tetraploid potato. Theor Appl Genet. 2017;130:123-35.

48. Bourke PM, Voorrips RE, Visser RGF, Maliepaard C. The double-reduction landscape in tetraploid potato as revealed by a high-density linkage map. Genetics. 2015;201:853-63.

49. Preedy KF, Hackett CA. A rapid marker ordering approach for high-density genetic linkage maps in experimental autotetraploid populations using multidimensional scaling. Theor Appl Genet. 2016;129:2117-32.

50. Luo ZW, Hackett CA, Bradshaw JE, McNicol JW, Milbourne D. Construction of a genetic linkage map in tetraploid species using molecular markers. Genetics. 2001;157:1369-85.

51. Li J, Das K, Fu G, Tong C, Li Y, Tobias C, et al. EM algorithm for mapping quantitative trait loci in multivalent tetraploids. Intl J Plant Genom. 2010. doi: 10.1155/2010/216547

52. Rosyara UR, De Jong WS, Douches DS, Endelman JB. Software for genomewide association studies in autopolyploids and its application to potato. Plant Genome. 2016;9:1-10. doi: 10.3835/plantgenome2015.08.0073

53. Bourke PM, Voorrips RE, Visser RGF, Maliepaard C. Tools for genetic studies in experimental populations of polyploids. Front Plant Sci. 2018;9:513. doi: 10.3389/fpls.2018.00513

54. Fischer RA. The theory of linkage in polysomic inheritance. Philos Trans R Soc London B. 1947;233:55-87.

55. Luo ZW, Zhang R, Kearsey MJ. Theoretical basis for genetic linkage analysis in autotetraploid species. Proc Natl Acad Sci U S A. 2004;101:7040-5.

56. Bourke PM, Voorrips RE, Kranenburg T, Jansen J, Visser RGF, Maliepaard M. Integrating haplotype-specific linkage maps in tetraploid species using SNP markers. Theor Appl Genet. 2016;129:2211-26.

57. Bartkiewicz AM, Chilla F, Terefe-Ayana D, Lübeck J, Strahwald J, Tacke E, et al. Maximization of markers linked in coupling for tetraploid Potatoes via monoparental Haploids. Front. Plant Sci. 2018;9:620. doi: 10.3389/fpls.2018.00620

58. Jacobs JME, Van Eek HJ, Arens P, Verkerk-Bakker B, te Lintel Hekkert B, Bastiaanssen HJM, et al. A genetic map of potato (Solanum tuberosum) integrating molecular markers, including transposons, and classical markers. Theor Appl Genet. 1995;91:289-300.

59. Felcher KJ, Coombs JJ, Massa AN, Hansey CN, Hamilton JP, Veilleux RE, et al. Integration of two diploid potato linkage maps with the potato genome sequence. PLoS One. 2012;7:e36347. doi: 10.1371/journal.pone.0036347

60. Endelman JB, Jansky SH. Genetic mapping with an inbred line-derived $\mathrm{F}_{2}$ population in potato. Theor Appl Genet. 2016;129:935-43.

61. Meijer D, Viquez-Zamora M, van Eck HJ, Hutten RCB, Su Y, Rothengatter R, et al. QTL mapping in diploid potato by using selfed progenies of the cross $S$. 
tuberosum $\times$ S. chacoense. Euphytica. 2018;214:121. doi: 10.1007/s10681-0182191-6

62. Hackett CA, Milne I, Bradshaw JE, Luo Z. TetraploidMap for Windows: Linkage map construction and QTL mapping in autotetraploid species. J Hered. 2007;98:727-9.

63. McCord PH, Sosinski BR, Haynes KG, Clough ME, Yencho GC. Linkage mapping and QTL analysis of agronomic traits in tetraploid potato (Solanum tuberosum subsp. tuberosum). Crop Sci. 2011;51:771-85.

64. Rak K, Bethke PC, Palta JP. QTL mapping of potato chip color and tuber traits within an autotetraploid family. Mol Breed. 2017;37:15. doi: 10.1007/s11032017-0619-7

65. Schumann MJ, Zeng Z-B, Clough ME, Yencho GC. Linkage map construction and QTL analysis for internal heat necrosis in autotetraploid potato. Theor Appl Genet. 2017;130:2045-56.

66. Strachan SM, Armstrong MR, Kaur A, Wright KM, Lim TY, Baker K, et al. Mapping the $H 2$ resistance effective against Globodera pallida pathotype Pa1 in tetraploid potato. Theor Appl Genet. 2019;132:1283-94.

67. Vleeshouwers VGAA, Raffaele S, Vossen JH, Champouret N, Oliva R, Segretin $\mathrm{ME}$, et al. Understanding and exploiting late blight resistance in the age of effectors. Annu. Rev. Plant Pathol. 2011;49:507-31.

68. Lenman M, Ali A, Mühlenbock P, Carlson-Nilsson U, Liljeroth E, Champouret $\mathrm{N}$, et al. Effector-driven marker development and cloning of resistance genes against Phytophthora infestans in potato breeding clone SW93-1015. Theor Appl Genet. 2016;129:105-15.

69. Jupe F, Witek K, Verweij W, Sliwka J, Pritchard L, Etherington GJ, et al. Resistance gene enrichment sequencing (RenSeq) enables reannotation of the NB-LRR gene family from sequenced plant genomes and rapid mapping of resistance loci in segregating populations. Plant J. 2013;76:530-44.

70. Li J, Lindqvist-Kreuze H, Tian Z, Liu J, Song B, Landeo J, et al. Conditional QTL underlying resistance to late blight in a diploid potato population. Theor Appl Genet. 2012;124:1339-50.

71. Sliwka J, Jakuczun H, Kamiñski P, Zimnoch-Guzowska E. Marker-assisted selection of diploid and tetraploid potatoes carrying Rpi-phu1, a major gene for resistance to Phytophthora infestans. J Appl Genet. 2010;51:133-40.

72. Colton LM, Groza HI, Wielgus SM, Jiang J. Marker-assisted selection for the broad-spectrum potato late blight resistance conferred by gene $R B$ derived from a wild potato species. Crop Sci. 2006;46:589-94.

73. Halterman DA, Middleton G. Presence of the potato late blight resistance gene $R B$ does not promote adaptive parasitism of Phytophthora infestans. Am J Plant Sci. 2012;3:360-7.

74. Jiang R, Li J, Tian Z, Du J, Armstrong M, Baker K, et al. Potato late blight field resistance from QTL dPI09c is conferred by the NB-LRR gene R8. J Exp Bot. 2018;69:1545-55. 
75. Vossen JH, van Arkel G, Bergervoet M, Jo KR, Jacobsen E, Visser RGF. The Solanum demissum $R 8$ late blight resistance gene is an $S w-5$ homologue that has been deployed worldwide in late blight resistant varieties. Theor Appl Genet. 2016;129:1785-96.

76. Myles S, Peiffer J, Brown PJ, Ersoz ES, Zhang Z, Costich DE, et al. Association mapping: critical considerations shift from genotyping to experimental design. Plant Cell. 2009;21:2194-202.

77. D’hoop BB, Paulo MJ, Visser RGF, van Eck HJ, van Eeuwijk FA. Phenotypic analyses of multi-environment data for two diverse tetraploid potato collections: comparing an academic panel with an industrial panel. Potato Res. 2011;54:157-81.

78. Stich B, Melchinger A. Comparison of mixed-model approaches for association mapping in rapeseed, potato, sugar beet, maize, and Arabidopsis. BMC Genomics. 2009;10:94. doi: 10.1186/1471-2164-10-94

79. Gebhardt C, Ballvora A, Walkemeier B, Oberhagemann P, Schuler K. Assessing genetic potential in germplasm collections of crop plants by marker-trait association: a case study for potatoes with quantitative variation of resistance to late blight and maturity type. Mol Breed. 2004;13:93-102.

80. Malosetti M, Van der Linden CG, Vosman B, Van Eeuwijk FA. A mixed-model approach to association mapping using pedigree information with an illustration of resistance to Phytophthora infestans in potato. Genetics. 2007;175:879-89.

81. Simko I, Costanzo S, Haynes KG, Christ BJ, Jones RW. Linkage disequilibrium mapping of a Verticillium dahliae resistance quantitative trait locus in tetraploid potato (Solanum tuberosum) through a candidate gene approach. Theor Appl Genet. 2004;108:217-24.

82. Pajerowska-Mukhtar KM, Stich B, Achenbach U, Ballvora A, Lubeck J, Strahwald J, et al. Single nucleotide polymorphisms in the allene oxide synthase 2 gene are associated with field resistance to late blight in populations of tetraploid potato cultivars. Genetics. 2009;181:1115-27.

83. Mosquera T, Alvarez MF, Jiménez-Gómez JM, Muktar MS, Paulo MJ, Steinemann S, et al. Targeted and untargeted approaches unravel novel candidate genes and diagnostic SNPs for quantitative resistance of the potato (Solanum tuberosum L.) to Phytophthora infestans causing the late blight disease. PLoS One. 2016;11:e0156254. doi: 10.1371/journal.pone.0156254

84. Juyo Rojas DK, Soto Sedano JC, Ballvora A, Léon J, Mosquera Vásquez T. Novel organ-specific genetic factors for quantitative resistance to late blight. PLoS One. 2019;14:e0213818. doi: 10.1371/journal.pone.0213818

85. Lindqvist-Kreuze H, Gastelo M, Perez W, Forbes GA, de Koeyer D, Bonierbale M. Phenotypic stability and genome-wide association study of late blight resistance in potato genotypes adapted to the tropical highlands. Phytopathology. 2014;104:624-33.

86. Fischer M, Schreiber L, Colby T, Kuckenberg M, Tacke E, Hofferbert H-R, et al. Novel candidate genes influencing natural variation in potato tuber cold sweetening identified by comparative proteomics and association mapping. BMC Plant Biol. 2013;13:113. doi: 10.1186/1471-2229-13-113 
87. Li L, Paulo M-J, Strahwald J, Lüubeck J, Hofferbert H-R, Tacke E, et al. Natural DNA variation at candidate loci is associated with potato chip color, tuber starch content, yield and starch yield. Theor Appl Genet. 2008;116:1167-81.

88. Li L, Strahwald J, Hofferbert HR, Lübeck J, Tacke E, Junghans H, et al. DNA variation at the invertase locus invGE/GF is associated with tuber quality traits in populations of potato breeding clones. Genetics. 2005;170:813-21.

89. D’hoop BB, Paulo MJ, Mank RA, van Eck HJ, van Eeuwijk FA. Association mapping of quality traits in potato (Solanum tuberosum L.). Euphytica. 2008;161:47-60.

90. Aliche EB, Oortwijn M, Theeuwen TMPJ, Bachem CWB, van Eck HJ, Visser RGF, et al. Genetic mapping of tuber size distribution and marketable tuber yield under drought stress in potatoes. Euphytica. 2019;215:186. doi: 10.1007/s10681-019-2508-0

91. Young ND, Tanksley SD. Restriction fragment length polymorphism maps and the concept of graphical genotypes. Theor Appl Genet. 1989;77:95-101.

92. van Eck HJ, Vos PG, Valkonen JPT, Uitdewilligen JGAML, Lensing H, de Vetten $\mathrm{N}$, et al. Graphical genotyping as a method to map $N y(o, n)$ sto and Gpa5 using a reference panel of tetraploid potato cultivars. Theor Appl Genet. 2017;130:515-28.

93. Uitdewilligen JG, Wolters AM, D’hoop BB, Borm TJ, Visser RG, van Eck HJ. A next-generation sequencing method for genotyping-by-sequencing of highly heterozygous autotetraploid potato. PLoS One. 2013;8:e62355. doi: 10.1371/journal.pone.0062355

94. Desta ZA, Ortiz R. Genomic selection: genome-wide prediction in plant improvement. Trends Plant Sci. 2014;19:592-601.

95. de Bem Oliveira I, Resende MFR Jr, Ferrão LFV, Amadeu RP, Endelman JB, Kirst M, et al. Genomic prediction of autotetraploids; influence of relationship matrices, allele dosage, and continuous genotyping calls in phenotype prediction. G3. 2019;9:1189-98.

96. Endelman JB, Schmitz Carley CA, Bethke PC, Coombs JJ, Clough ME, da Silva WL, et al. Genetic variance partitioning and genome-wide prediction with allele dosage information in autotetraploid potato. Genetics. 2018;209:77-87.

97. Slater AT, Cogan NOI, Forster JW, Hayes BJ, Daetwyler HD. Improving genetic gain with genomic selection in autotetraploid potato. Plant Genome. 2016;9. doi: 10.3835/plantgenome2016.02.0021

98. Sverrisdóttir E, Sundmark EHR, Johnsen HØ, Kirk HG, Asp T, Janss L, et al. The value of expanding the training population to improve genomic selection models in tetraploid potato. Front Plant Sci. 2018;9:1118. doi: 10.3389/fpls.2018.01118

99. Sverrisdóttir E, Byrne S, Sundmark EHR, Johnsen HØ, Kirk HG, Asp A, et al. Genomic prediction of starch content and chipping quality in tetraploid potato using genotyping-by-sequencing. Theor Appl Genet. 2017;130:2091108. 
100. Stich B, Van Inghelandt D. Prospects and potential uses of genomic prediction of key performance traits in tetraploid potato. Front Plant Sci. 2018;9:159. doi: 10.3389/fpls.2018.00159

101. Habyarimana E, Paris B, Mandolino G. Genomic prediction for yields, processing and nutritional quality traits in cultivated potato (Solanum tuberosum L.). Plant Breed. 2017;136:245-52.

102. Enciso-Rodriguez F, Douches D, Lopez-Cruz M, Coombs J, de los Campos G. Genomic selection for late blight and common scab resistance in tetraploid potato (Solanum tuberosum). G3. 2018;8:2471-81.

103. Sverrisdóttir E. Initiating genomic selection in tetraploid potato [PhD Thesis]. Aalborg (Denmark): Faculty of Engineering and Science, Aalborg University; 2017.

104. Bradshaw J. Review and analysis of limitations in ways to improve conventional potato breeding. Potato Res. 2017;60:171-93.

105. Slater AT, Cogan NOI, Rodoni BC, Daetwyler HD, Hayes BJ, Caruana B, et al. Breeding differently-the digital revolution: high-throughput phenotyping and genotyping. Potato Res. 2017;60:337-52.

106. Prashar A, Yildiz J, McNicol JW, Bryan GJ, Jones HG. Infra-red thermography for high throughput field phenotyping in Solanum tuberosum. PLoS One. 2013;8:e65816. doi: 10.1371/journal.pone.0065816

107. Bernhard T, Truberg B, Friedt W, Snowdon R, Wittkop B. Development of near-infrared reflection spectroscopy calibrations for crude protein and dry matter content in fresh and dried potato tuber samples. Potato Res. 2016;59:149-65.

108. Stokstad E. The new potato. Science. 2019;363:574-8.

109. Lindhout P, Meijer D, Schotte T, Hutten RCB, Visser RGF, van Eck HJ. Towards F1 hybrid seed potato breeding. Potato Res. 2011;54:301-12.

110. Jansky SH, Charkowski AO, Douches DS, Gusmini G, Richael C, Bethke PC, et al. Reinventing potato as a diploid inbred line-based crop. Crop Sci. 2016;56:111.

111. de Vries M, ter Maat M, Lindhout P. The potential of hybrid potato for EastAfrica. Open Agric. 2016;1:151-6.

112. Jansky SH, Spooner DM. The evolution of potato breeding. Plant Breed Rev. 2018;41:169-214.

113. Phumichai C, Mori M, Kobayashi A, Kamijima O, Hosaka K. Toward the development of highly homozygous diploid potato lines using the selfcompatibility controlling Sli gene. Genome. 2005;48:977-84.

114. Ye M, Peng Z, Tang D, Yang Z, Li D, Xu Y, et al. Generation of self-compatible diploid potato by knockout of S-RNase. Nat Plants. 2018;4:651-3.

115. Taylor M. Routes to genetic gain in potato. Nat Plants. 2018;4:631-2.

116. Andersson M, Turesson H, Olsson N, Fält A-S, Olsson P, Gonzalez MN, et al. Genome editing in potato via CRISPR-Cas9 ribonucleoprotein delivery. Physiol Plant. 2018;164:378-84. 
117. Andersson M, Turesson H, Nicolia A, Fält A-S, Samuelsson M, Hofvander P. Efficient targeted multiallelic mutagenesis in tetraploid potato. Plant Cell Rep. 2018;36(1):117-28.

How to cite this article:

Ortiz R. Genomic-Led Potato Breeding for Increasing Genetic Gains: Achievements and Outlook. Crop Breed Genet Genom. 2020;2(2):e200010. https://doi.org/10.20900/cbgg20200010 